\title{
BLOGGING ONLINE LEARNING NEWS AND RESEARCH
}

\author{
Ray Schroeder \\ Professor Emeritus and Director of Technology-Enhanced Learning \\ University of Illinois at Springfield \\ Springfield, IL 62703 \\ (217) 206-7531
}

Fax (217) 206-7539

\begin{abstract}
Those in the field of ALN are confronted with the challenge of keeping up with the rapidly evolving processes, technologies, environments and current findings of the field. As director of technologyenhanced learning at the University of Illinois at Springfield (UIS), I am charged with seeking out the latest developments and sharing them with our online faculty members. In this case study, I describe the process of identifying current developments, filtering them to meet faculty interests and the use of web $\log$ (blog) technologies to disseminate the information to faculty members at UIS and elsewhere.
\end{abstract}

\section{KEY WORDS}

Web log, Blog, Online Learning Update, Faculty Satisfaction, Learning Effectiveness

\section{INTRODUCTION}

Those who seek to develop effective practices in this field are best served with an exposure to a wide range of alternative approaches and a steady stream of updates on current research. The technologies and practices of online learning continue to evolve on nearly a daily basis. There is no central repository of information relevant to this field. Yet only through exposure to this information can faculty members make an informed selection of the most appropriate and relevant technologies and techniques to apply to their discipline and students. Well-informed faculty members can make the best choices in this rapidly changing field. Informed faculty members are also best able to collaborate with the technology staff in developing custom online environments for their classes.

The challenge, then, is really three-fold. First, one must identify sources for information on the latest technologies, research and related developments in this rapidly changing field. Second, one must filter this information to select the items most relevant to faculty members. Third, one must deliver the information to faculty members who are busy with their discipline-area research and teaching responsibilities. Ideally, one would be able to deliver the information in such a way that it easily can be skimmed, perused in detail, archived and recalled through keyword search. And, of course, it must be available $24 \times 7$ to meet varied schedules.

\section{CASE STUDY}

The University of Illinois at Springfield is an evolving institution. The campus originated in 1970 as Sangamon State University, an upper division (junior/senior year) and master's level university. With a 
largely commuter student population, the campus served the state capital of Springfield, the surrounding rural towns and a handful of small cities within commuting distance. In 1995, the campus became part of the University of Illinois system. At very nearly the same time, the administration of University of Illinois began to encourage faculty members on the campuses to experiment with online technologies to expand and enhance the teaching and learning process.

Over the intervening years, the online program at UIS has grown to include more than 1,000 students taking a wide range of courses, including six online degree programs (two master's level and four baccalaureate degree completion). Now, one out every four UIS students is taking at least one online class; one out of eight is only taking online classes. This case study will examine the variety of means we employed in addressing the issue of disseminating information about best practices and emerging issues and technologies to the faculty members at UIS. In addition, I will discuss some unanticipated outcomes in terms of off-campus interest in the blogs.

\section{A. Office of Technology-Enhanced Learning (OTEL)}

In 1997, as part of the process of encouraging the use of online technologies, the University of Illinois Vice President for Academic Affairs, Dr. Sylvia Manning, funded the development of an Office of Technology-Enhanced Learning on the Springfield campus. With daily assistance from the director of the University of Illinois Online Office, then-Assistant Vice President for Academic Affairs, Dr. Burks Oakley, I was given charge of the new unit. The core of the mission of the unit was to:

- Inform Faculty: Inform all UIS faculty of the vast resources and significant potential of the Internet to facilitate and enrich the teaching/learning process; community and specialized service; and select research activities.

- Empower Faculty: Give faculty the understanding, tools and skills to effectively identify resources on the Internet, to obtain information from the Internet, and to effectively share their knowledge and information by originating material on the Internet and engaging in interactive communication with students.

- Assist and Encourage Faculty: Aid faculty in employing the Internet and associated technologies to more effectively fulfill their teaching, service and scholarship responsibilities.

- Provide continuing support for faculty as they utilize technologies to enhance the learning process.

- Create a Vision: Develop exemplar learning environments that can stimulate the imagination and creativity of faculty to conceptualize environments that will best meet their students' needs.

Clearly, in order to meet the goals of informing, empowering, assisting, encouraging, and creating a vision for faculty members on the campus, I would need to find a way to identify, select and communicate the best practices, technologies and related developments in this field.

\section{B. Initial Approach to Identifying, Selecting and Disseminating Emerging Information on Online Learning and ALN}

In 1997, it was easy enough to peruse a high percentage of the relatively few relevant journals and news sources as they were published. While a number of the academic computing and educational technology publications addressed this emerging field of online learning, there were only a relative handful that of sources of information. I would scan the publications and send out copies of articles that seemed relevant to our circumstances at UIS to the handful of interested faculty. Over time, I began a regular 
process of seeking and identifying sources for information on online learning. No specific rubric was established for selection of items, rather I applied my understanding of the individual needs and interests of the faculty members.

I began an online notebook of sources in this field, The Online Learning Notebook (http://people.uis.edu/rschr1/sources.htm). I developed a listserv to share this information with colleagues and students in my "New Technologies in the Electronic Media" graduate seminar. In addition, I sought out discipline-based resources. Faculty members became accustomed to receiving emails from the director of OTEL with "of possible interest" in the subject line. They knew that these contained Internet resources that the director had identified as relating to their teaching or research areas.

As the online initiative grew, we began to get more and more faculty members interested in teaching online. Concurrently, the number of journals and news publications that addressed this field was growing. The original listserv continued to grow as graduate students who left for doctoral programs or careers with educational and other institutions around the country remained on the list. And word spread with requests from others in the field seeking to find a way to get a handle on this rapidly changing field. I split the listserv into two different lists (with numerous dual subscribers): one covering items of particular interest to those who supported technology in higher education and the second one with items specific to online learning in higher education.

By February 2000, I began experimenting with the then, rather new blogger system of dynamically creating web pages comprised of chronological postings. The system offered a simple online html editor with ftp transfer of files to remote servers. An auto-archive feature was included with the system so that postings could be saved and tracked over time. In mid-June, 2001, I began regular daily postings of the two listservs to separate blogs.

Beginning at 5:30 a.m. seven days a week, I survey a series of news and journal sources for potential items to blog. I post at least three items to each of the Online Learning Update and Techno-News blogs each morning. The intent is to assure that that there are half a dozen new items waiting for our faculty and staff when they arrive at work by 8:30 a.m. each morning. Many mornings, there are far more than half a dozen interesting items, but, with rare exception, I maintain the three daily postings per blog in an effort to assure that I don't overwhelm readers with too many items and don't dilute the overall quality and relevance of selections. Each item carries a hyperlinked headline with two or three sentences of text from the article to give readers a quick sense of the contents of each item.

\section{News Sources}

A rich variety of sources of news, research and related information on online learning is emerging. New academic journals have sprung up, while others have failed to continue publication. Fortunately, an increasing number of journals are available online. Publications that are less scholarly, such as national newspapers, including the Chronicle of Higher Education, have come to provide regular coverage of new developments in the ALN field. The range of publications on my "daily news readings" list (http://people.uis.edu/rschr1/news.htm) provides a continuum of news coverage from the release of technologies through reports of new online initiatives to carefully designed empirical studies of effectiveness of online learning approaches. Among the daily news readings are other technology blogs and meta-news sources.

An important tool I use in identifying news articles relating to online learning and ALN from publications 
around the world is the http://news.google.com search function. One is able to search 4,500 news publications by word or phrase as well as order those results by time of publication. This enables me to identify new reports from original publications days before they find their way into the national press.

\section{Readership of the Blogs}

In the first months of dissemination of reports through the blogs, the Web Counter indicated that each blog received a couple of dozen hits a day. These visits, presumably, were largely from the established base of UIS faculty and staff members. Over time, the number picked up.

In May, 2002, I subscribed to http://www.sitemeter.com and enabled data collection on the Online Learning Update blog. A wealth of information about readership is now available to those who visit the blog. Far more readers visit the site on weekdays than weekends. On an average day, 130 different visitors view the blog. The site tracking by time zone feature commonly shows that persons in 18 or more different time zones around the world have visited the blog in the past few hours.

Perhaps most interesting is the large number of visitors who come to the blog from Google, Yahoo, and other search engines (see: http://www.sitemeter.com/default.asp?action=stats\&site=s10learning \&report=11). The Google site-ranking algorithm is particularly favorable to the Online Learning Update blog. When one enters the term "online learning" into Google, the blog is the eighth site listed (not including "sponsored" links).

It is also interesting to note that a growing number of related blog and university technology sites are linking to the Online Learning Update. Google, among other search engines, provides a tool through which one can identify Web pages that have links to a given URL (see: http://www.google.com/ search?hl=en\&ie=UTF-8\&oe=UTF-8\&q=link\%3Ahttp\%3A\%2F\%2Fpeople.uis.edu\%2Frschr1\%2F onlinelearning\%2Fblogger.html).

\section{E. Rich Site Summary (RSS) Syndication and Aggregation}

RSS syndication uses XML to format files that list a summary of the recently posted content of a blog or another such news or information site. Aggregation of RSS enables users to collect the basic text of one or many publications into a file that can be displayed in a number of ways. A number of popular RSS aggregators exist that facilitate the collection of updated feeds and display them on the Web, on the desktop or via email. One such aggregator is http://www.newsisfree.com. Newsisfree, for example provides those who subscribe to the free service a custom web page that displays the subscriber-selected RSS feeds from any of hundreds of sources. A daily email is also sent to the subscriber with the selected RSS updates.

I added automatic generation of an RSS XML file for each of the blogs. So, an unknown number of readers collect the information that is posted on the blog and view it via their own RSS aggregator.

\section{F. Two-Way Communication Via Blogs - The Comment Option}

I have begun experimenting with a comment feature on a third blog. If successful, I will include this on the Online Learning Update and Techno-News. The comment feature enables readers to publicly post their comments on blog items. Other readers may comment upon the comments. This facilitates community sharing of views and information through the blog site. The editor of the blog maintains 
editorial control of the comments and may delete selected comments and even prohibit postings from selected IP addresses.

\section{CONCLUSIONS AND POTENTIAL FOR OTHER INSTITUTIONS}

As documented through Google and Site Meter, the readership for these blogs extends around the world. Interest continues to grow. It seems that the blogs are meeting a need at a number of institutions. It is gratifying that others have found them useful. Yet, the focus of the blogs remains to serve the faculty and staff at UIS. While interests at other institutions are certainly similar, there remain challenges and opportunities that are unique to each institution. Therefore, it would seem appropriate that other institutions use this method to modify the content of these blogs or to create new and unique blogs to more precisely meet their needs to communicate with the faculty and staff engaged in the online learning process.

The efficiency of the blog with the associated hyperlinks, RSS syndication and comment features provides a model for communication that can fit into the very busy lifestyle academics and technologists who are engaged in this field. It provides a ready means of identifying key news and research on a daily basis. The archive function of the blog enables word search of the titles and brief summaries. Over time, as the archives grow, they become more and more valuable as a means to track changing technologies, pedagogies and viewpoints in online learning.

The blogs serve a function of linking faculty, staff and students who share an interest in this field. With the comment function, the potential exists to create on-going dialog among readers on issues and technologies.

\section{THE BLOGS}

1. Online Learning Update http://people.uis.edu/rschr1/onlinelearning/blogger.html

2. Techno-News Blog http://people.uis.edu/rschr1/blogger.html

3. Educational Technology http://people.uis.edu/rschr1/et/blogger.html

\section{ABOUT THE AUTHOR}

Ray Schroeder is Professor Emeritus of Communication, Director of the Office of Technology-Enhanced Learning at the University of Illinois at Springfield and Faculty Associate at the University of Illinois Online. He has taught more than a dozen online classes. As Director of Technology-Enhanced Learning he leads the campus online initiative. As Faculty Associate, Schroeder is engaged in the formation of online learning policy for the University of Illinois. He is a Sloan Consortium Distinguished Scholar in Online Learning 2002-2003 and the recipient of the Sloan Consortium Most Outstanding Achievement in ALN by an Individual Award 2002. 